\title{
Management bias as a cause of employee weak performance: Case Study at Jadara University
}

\author{
Khaled Abdel Kader Alomari ${ }^{\text {* }}$
}

aBusiness Management, Jadara University, Jordan

CHRONICLE ABSTRACT

Article history:

Received: October 14, 2019

Received in revised format: No-

vember 292019

Accepted: January 9, 2020

Available online:

January 9, 2020

Keywords:

Management Bias

Employee weak performance

Jadara University

\begin{abstract}
The study seeks to define the role of management bias on the weak performance of employees. The research sample comprised of 107 male and female employees. To achieve this research purpose, there were 79 questionnaires valid for statistical analysis, adopting the descriptive approach. Questionnaire was used to measure the effect of management bias on employees' weak performance. The study concluded that the university dependence on scientific foundations, qualifications, and abilities in selecting and recruiting employees was intermediate, which indicates that the university does not often follow the right regulations in selecting employees, indicating the bias existing in employees' selection. In light of the aforementioned results, the study recommended the management at Jadara University to establish an independent committee of professionals to recruit efficient and qualified employees.
\end{abstract}

\section{Introduction}

Management bias did not draw researchers' and practitioners' attention in the past, as it is a modern concept that has lately been associated with the science of business management. Across different organizations, management bias practices frighten employees and it negatively affects the employee's performance, which in turn influences achieving organization goals. Practicing organizations bias, including all its types, alters employee's behavior into a positive bias which demonstrates employee's dependency on the management and favoritism by the management toward the employee, therefore, task performance fails. On the other hand, the organization's bias can be negative towards certain employees, leading to dissatisfaction among others. In addition, performance and organization goals will be negatively influenced. By this result the current study was provoked to find the causes of bias and its reflection on employees, resulting in weak efficacy and effectiveness and influencing the organization in general. A competitive complex environment was generated by the technical development, openness, and free flow of goods, services, ideas, and money, which made bias generally, and management bias specifically; one of the most important challenges that face business organizations. Achieving effectiveness and efficacy in any organization is strongly related to good management. Effectiveness and efficacy are negatively influenced by bias, mediation, and favoritism prevalence in Arab organizations generally, and organizations in Jordan in specifically; moreover, it is necessary for researchers to explore this topic. The current study seeks to examine the topic in an educational organization that offers educational services; "Jadara University". The study attempted to answer the following main question "is there an effect of management bias practice and its dimensions on employee's performance at Jadara University?" several questions emerge from the main question: Is there an effect of management bias practice in selection and recruitment on employee's performance at Jadara University? Is there an effect of management bias practice in evaluation and promotion on employee's 
performance at Jadara University? Is there an effect of management bias practice in offering incentives and rewards on employee's performance at Jadara University? Is there an effect of management bias practice in job security on employee's performance at Jadara University? In the current research, the theoretical aspect aims to examine the phenomenon of management bias and contribute to global and Arab literature, whereas the practical aspect is recognizing the role of management bias in employee's performance at Jadara University. The results may help us provide recommendations that may help higher management at the university and Arab organizations to enhance employee's performance and increase their satisfaction.

The current study is driven by achieving several objectives. First, it aims to identify the level of management bias and its dimensions at Jadara University. In addition, the study seeks to identify the impact of management bias level on employees' performance at Jadara University. Moreover, it aims to identify the effect of management bias practice and its dimensions on employees' performance at Jadara University. Another objective of this study is to illuminate researchers about management bias to provoke them to study the topic more to add literature to the Arab and global libraries. Finally, it aims to provide recommendations that will benefit Jadara university managers, and enhance performance.

\section{Theory and Hypotheses}

\subsection{Management Bias}

It was considerably agreed among researchers that bias concept refers to collect and grouping, affiliation, or tendency toward another situation (Haroon, 1990). As mentioned in Lisan al-Arab dictionary, when people are biased them "leave their position and leaned into another." Management bias is a managerial phenomenon influencing employee's performance stability and development, in addition to organization goals. This sort of management has resulted from decision-makers' favoritism towards a certain employee, or towards a division; to satisfy their implicit needs and real bias reasons by a legal coverage, all of which reflects on employee's performance in the organization (Mostafa, 2009). Several types are included in management bias. The first type appears in the form of selecting individuals despite not meeting the job requirements or even the privation of vacancies. Bias after employment is more common, as biased employees will be assigned with less effort, few commitment-hours tasks, higher-paid positions, and widely-authorize despite their lack of experience, ability to benefit their work. Bias also includes offering employee rewards and promotions although they do not deserve it, and they are not required to take responsibility for their work mistakes, in addition to the lack of working hour's commitment.

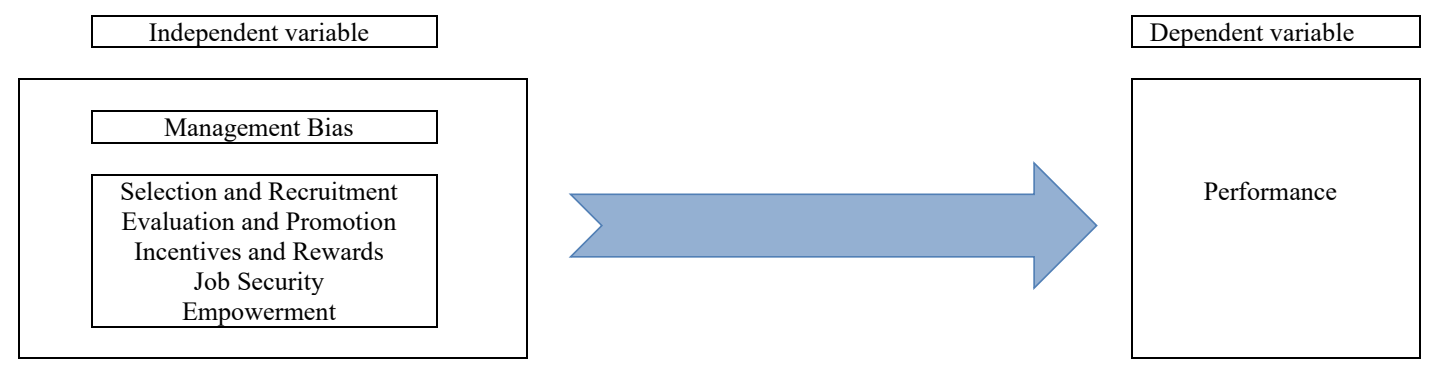

Fig. 1. Model of the study

It is certain fact that management bias negatively affects organizations, resulting in weak performance, low levels of satisfaction and inability to achieve, effectively and efficiently, the organization's goals. Management bias is also accompanied by employee's slack, creativity destruction, and job leakage due to injustice and bias frustration. Bias emerges when we explain things from a certain self-perspective and takes different forms, such as biasness to a certain area, cline, gender, age group, hoppy, major (Hajelan, 2011; Aljawarneh, \& Atan, 2018), or a culture (Freimuth, 2014). Bias emerges when we explain things from a certain self-perspective. Organizations should, therefore, tackle the phenomenon by implementing governance standards, justice, integrity, transparency, equality, job behaviors, social responsibility, and to increase employee's awareness of commitment. In addition, administrative communication channels should be created by management between all employees according to the job level. Moreover, standards and job descriptions should be made to increase control styles. Several reasons cause management bias, according to Abo Al-Azem (2015). Firstly, it is caused by the lack of cognitive abilities among senior management team. Secondly, it resulted from the lack of information required to evaluate performance, especially the strategic information. Finally, it is resulted from the psychological burden of evaluating employees because of the relations with the subordinates. According to the modern bias literature, there are three types of management bias. First type is general standards bias and it occurs due to the huge given relative weights by senior managers for the general standards; which are financial and associated with previous performance and achievement volume, while small relative weights or zero weight are given for the special standards that are associate with future performance such as plans and visions (Kaplan \& Norton, 1996). Another type of management bias is central bias which arises when employees and head departments are evaluated similarly by senior managers, despite minor differences between them (Bol, 2011). Regarding 
income and performance, in central bias employees exert more effort than the others with less income, although in normal circumstances the normal relation between the income and performance should be positive, hence, more performance should lead to more income. Finally, lenient bias occurs when senior management evaluation degrees of head departments and employees are higher than the degrees of their actual performance (Bol, 2011). Higher evaluations satisfy low-performance employees and head departments, as they are being overrated, which might negatively affect other employee's performance; as their exerted effort is being wasted, without getting a raise in their salary or positions. On the contrary, high-performance employees and head departments will feel injustice due to their low-performance peers that are getting high evaluations. The researcher believes that previous mentioned bias types negatively influence the performance.

\subsection{Employees' Weak Performance}

In many business domains, the term performance evaluation spread widely. It was defined by several scholars but none of them gave a unified definition combining various scientific viewpoints. Al-Khasawneh et al. (2018) for instance, defined performance as a system that reviews employee's performance in the assigned tasks and compares employees' performance with specified indicators in order to achieve the organizations sought goals. In this respect, Thabit (2015) stated that "performance evaluation" is a system that measures and analyzes the employee's performance of assigned to judge their efficacy and development potentials in work in the future. Performance evaluation is an important administrative task that pursues judging the accuracy of the procedures and programs adopted in the organization to manage and follow up human resources starting from attraction and selection to training and developing, which is reflected in the organization performance and goals achievement. Performance evaluation from the employee viewpoint is "a media that gives the employee an ability to recognize his performance strengths and weaknesses" by the evaluation results, so he can develop strengths and manage the weaknesses to enhance performance. Many organizations achieve goals with proficiency; normal performance fails to encounter the changes and competition, so performance evaluation developed as an important trend that affects work efficacy. Consequently, performance evaluation has become the dominant administrative phenomenon in organizations that adopt decisions related to employees along with the organization.

Performance, according to Shaker and Hamode (2011), is considered to be an important issue in all organizations, therefore, it is measured to ensure the performance efficacy by achieving a balance between the quantity factors and other measurements such as financial and nonfinancial factors. Hence, performance reflects the organization critical factors of success and determines the dimensions and scales suitable to its activities, and gives relative importance accordingly. Rapid change and development in modern business environments influenced the quantity and quality of information obtained by the organization to be able to measure performance, evaluates performance, and achieves different goals, as mentioned by (Aljawarneh \& AlOmari, 2018; Al-Omari et al., 2020). Moreover, the urgent need persists to develop traditional measurements of performance evaluation; particularly these related to financial domains, as it fails to keep pace with the successive developments of technology and its different means (Dodeen, 2009).

Performance evaluation plays an important role in successful organizations; as managements take important decisions for developing employee's performance levels, which in turn reflects on the organization performance level. Evaluation levels are influenced by several factors that prevent getting accurate and actual results, Al-Sa'doon (2013) confirmed that the personal tendencies, empathy, and personal relations influence performance evaluation too; therefore, these factors should be constrained to obtain true evaluations. The current study attempted to illustrate the employee's actual performance at Jadara University and to find whether management bias influences it, hoping to enhance the process of employee's performance evaluation. The evaluation performance process is influenced too by behavioral styles that are considered humankind actions and activities influenced by the surrounding environment and systems (Ibrahim, 2004). The evaluator's commitment to the regulations of the organizations has a great impact in the evaluation process. According to Abd Albaqi (2001), the evaluators might tend to use behaviors that endanger the evaluation process such as bias, personal favoritism, leniency, extremism, centrality, and confusion. The author stressed that the management style employed (democratic or dictatorial) has a fundamental impact on the evaluation process. The democratic style achieves harmony and understanding between the subordinate and employee, it enhances the employee sense of security and stability and allows the employees to develop and progress in future, this style influence evaluation because the employee's goals may override the organization goals. While the dictatorial style affects performance evaluation in a negative manner, it increases employee tension and psychological distress, destroys creativeness and losses communication between the subordinate and employee (Talal, 2013). Literature in management bias is relatively inconsiderable; as most of the research in bias explored different types other than management bias; which made it difficult to finds similar studies for review and comparison. For instance, Malkawi and Al-Omari (2018) examined the effects of management information system on organizations performance from Jordanian universities business academician's viewpoint. Deans and head departments of business faculties in public and private universities participated in the study. They found a significant direct correlation between management information system and organizations performance. In another research, Kagaari et al. (2010) examined the correlation between the practices of performance management, attitudes of employees and managed performance. In another study, the effect of bias on manager's performance evaluation was examined by Bol (2011), focusing on the lenient and central bias. The study concluded that managers respond to their incentives and personal interests when the evaluation of performance is personal. The cost of collecting the data and the powerful 
relationship between the subordinate and the employee influence the central and lenient bias positively. Bias influences current performance evaluation and employee's motivation in the future. The effect of the central bias on the performance enhancement was negative, but the correlation between performance and lenient bias was not negative. Al-Gharaibeh, and Malkawi (2013) examined the effects of management information systems on the governmental performance of the Ministry of Planning. Employees from the ministry (No. 77) answered the test items designed for the purpose of the study. They did not find an impact of the hardware and software tools on the employee's performance, but networks, individuals and the overall management information system influenced the performance. The authors recommend managers in the ministry to update the systems always, involve the employees in creating and receiving training on the system. Abo Al-Azem (2015) examined the impact of the professional and managerial senior management team background on bias, using a balanced scorecard to evaluate the performance of head departments. Study participants were head departments from banks and insurance companies in Egypt. Deductive approach was used to examine the collected data, and concluded three practiced types of bias in the financial sector in Egypt: central, lenient, and general standards biases. The correlation between management background and the general standard bias was positive, and it was negative with the general standard bias. While managerial and professional background did not correlate with the central and lenient bias. Recently, Prater et al. (2017) investigated previous researches results about causes of optimism bias, problems with reference schedules development, and examined optimism bias moderation techniques. It was concluded that optimism bias led to unrealistic scheduling, the researchers noticed the problem and used two common moderation techniques: Flyvbjergs' "reference class" and Kahnemans' "outside view." The effect of these techniques lacked empirical evidence especially for other types of projects or non-engineering projects. Martin (2017) studied the effects of strategic interventions framing to control cognitive bias by choice. He tested interviews designed to find the cognitive bias. The study included two experiments one with 146 of business students and a second with 48 senior decision makers. He found that the strategic interventions might work as a reframing process of cognitive bias. Adopting methods of choice presentation increased, preferences changes showed that including the right reference point within the communication might frame the choice of the decision positively. Therefore, framed interventions and an implicit reference point can disable bias. In a very recent study, Malkawi and Al-Omari (2018) explored the impact of organizational injustice on organizational conflict management at Jordanian Marseilles Company for Real Estate Investments. They found that the level of the organizational justice and organizational conflict management applied in the company is high. The effects of organizational justice on organizational conflict management are significant. The authors recommend the company management to increase implementing organizational justice in organizational conflict management. The study relies on the following hypotheses:

$\mathrm{H}_{1}$ : Management bias practice and its dimensions influence on employee performance at Jadara University.

$\mathrm{H}_{2}$ : Management bias practice of selection and recruitment influence on employee performance at Jadara University.

$\mathrm{H}_{3}$ : Management bias practice of evaluation and promotion influence on employee performance at Jadara University.

$\mathrm{H}_{4}$ : Management bias practice of offering incentives and rewards influence on employee performance at Jadara University.

$\mathrm{H}_{5}$ : Management bias practice of job security influence on employee performance at Jadara University.

$\mathrm{H}_{6}$ : Management bias practice of empowerment influence on employee performance at Jadara University.

\section{Methodology}

In this study, the descriptive analytical method was used, it describes the phenomenon accurately and expresses it quantitatively. The study population consisted of 107 Jadara University employees in 2018. 79 Questionnaires were distributed all of which were appropriate for analysis, with a retrieval rate score of (74\%). Two types of information were relied on: secondary sources such as books, researches, periodicals, and bulletins on management bias, and the test that comprised the primary source of information. Several lecturers were asked to review the test items importance, appropriateness, and linguistic adequacy. The internal consistency of the items adopting Cronbach Alpha method was (76\%), the accepted degree of consistency of social sciences studies score (70), so the score of this study is acceptable, and the results are reliable. Table 1 illustrates the values of the stability coefficient of each domain and the number of the constituent items.

Table 1

Stability coefficient (Cronbach's alpha) values of each domain and items number

\begin{tabular}{llcc}
\hline Variables & Domains & Items No. & Cronbach's Alpha coefficient value \\
& Selection and recruitment & 6 & $\% 81.3$ \\
& Evaluation and promotion & 6 & $\% 15.1$ \\
& Incentives and rewards & 4 & $\% 56$ \\
Management bias & Job security & 5 & $\% 53$ \\
& Empowerment & 6 & $\% 80.1$ \\
\cline { 2 - 4 } & Total & 27 & $\% 74$ \\
\hline Performance & & 12 & $\% 76$ \\
Overall & & 39 & $\% 76$ \\
\hline
\end{tabular}

\subsection{Data Analysis}

SPSS was used in the analysis of the data, mean and standard deviations to calculate the responses of the employee's answers on each item, and simple linear regression was used to test the hypotheses. Fig. 1 illustrates the sample distribution according to gender, age, experience, and academic qualifications. 


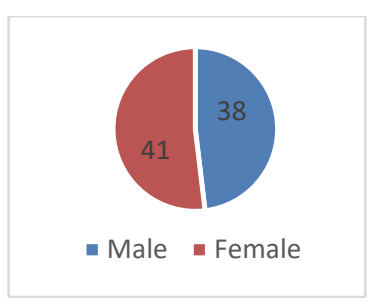

Gender

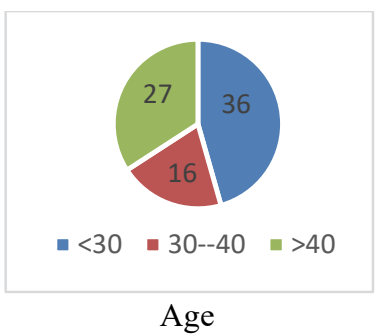

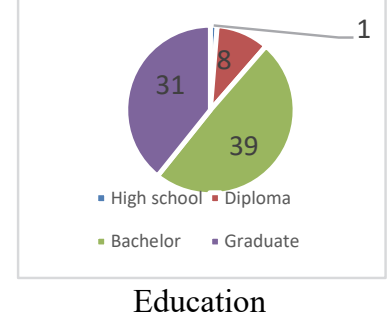

Education

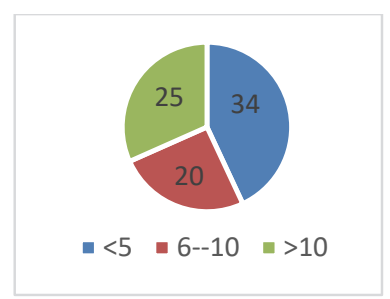

Years of job experience

Fig. 2. Personal characteristics of the participants

Fig. 2 illustrates that males and females' numbers are similar, most of them hold bachelor degrees, and the majority of their age group is less than 30 years. The experience employees have is less than five years, this refers to the fact that the organization is not keen to select and recruit experienced employees.

\section{Results and hypotheses tests}

The natural distribution of the data (Kolmogorov-Smirnov) was implemented, the results illustrated that the significance of all the variables scores more that $5 \%$ as seen in Table 2 . Table 3 illustrates the means, standard deviations and ranks of the management bias.

Table 2

$\underline{\text { Kolmogorov-Smirnov test value of data (Degree of Freedom }=79 \text { ) }}$

\begin{tabular}{lcccccccc}
\hline Variable & $\begin{array}{c}\text { Selection and } \\
\text { recruitment }\end{array}$ & $\begin{array}{c}\text { Evaluation and } \\
\text { promotion }\end{array}$ & $\begin{array}{c}\text { Incentives } \\
\text { and rewards }\end{array}$ & $\begin{array}{c}\text { Job } \\
\text { security }\end{array}$ & Empowerment & Bias & Performance \\
\hline Kolmogorov-Smirnov & 0.079 & 0.087 & 0.082 & 0.080 & 0.088 & 0.082 & 0.074 \\
Sign. & 0.160 & 0.220 & 0.240 & 0.180 & 0.210 & 0.200 & 0.170 \\
\hline
\end{tabular}

Table 3

Variables of management bias means and standard deviations

\begin{tabular}{|c|c|c|c|c|}
\hline Item No. & Average & Std. & Rank & Assessment \\
\hline Selection and recruitment & 2.909 & 0.601 & 1 & Intermediate \\
\hline Evaluation and promotion & 2.896 & 0.323 & 2 & Intermediate \\
\hline Incentives and rewards & 2.822 & 0.501 & 3 & Intermediate \\
\hline Job security & 2.769 & 0.447 & 4 & Intermediate \\
\hline Empowerment & 2.510 & 0.529 & 5 & Intermediate \\
\hline Management bias overall & 2.779 & 0.275 & & \\
\hline
\end{tabular}

According to Table 3, average and standard deviations of management bias dimensions overall score is intermediate, the differences are insignificance, selection and recruitment score ranked first and empowerment ranked last, this result refers to an intermediate management bias level correlation with the various dimensions.

Table 4

The mean and standard deviation of the factors associated with selection and recruitment

\begin{tabular}{|c|c|c|c|c|c|}
\hline & Item & Mean & $\begin{array}{l}\text { Std. } \\
\text { dev. }\end{array}$ & Rank & Level \\
\hline 1 & Employees are selected based on the qualifications required to occupy the job without bias & 3.113 & 0.800 & 2 & Intermediate \\
\hline 2 & Employees are tested depending on job descriptions & 3.151 & 0.717 & 1 & Intermediate \\
\hline 3 & Employees are recruited by advertising the job in different media means & 2.949 & 0.860 & 3 & Intermediate \\
\hline 4 & Employees are recruited through interviews and tests. & 2.886 & 0.947 & 4 & Intermediate \\
\hline 5 & Employees are recruited according to the standard hierarchy at the university. & 2.683 & 0.776 & 5 & Intermediate \\
\hline 6 & Employees are paid according to the applicable system of the job & 2.679 & 0.901 & 6 & Intermediate \\
\hline \multicolumn{2}{|r|}{ Overall means and standard deviation } & 2.909 & 0.601 & & Intermediate \\
\hline
\end{tabular}

As shown in Table 4, the mean and standard deviations scores of the selection and recruitment is intermediate in general, item "Employees are tested depending on job descriptions" scored (3.151). This result means that management bias tends to exist in the process of selection and recruitment and the level is intermediate, and the employee academic degree and required qualifications are not accounted for. The lowest mean score is for item "Employees are paid according to the applicable system of the job," which means the bias toward occupying the job is more important than paying the occupier a high salary. According to the results of Table 5, the information associated with mean and standard deviation of evaluation and promotion scores are intermediate, item "Management bias for some employees at Jadara University influences the performance of other employees negatively" scored the highest. This result means that the bias in evaluation and promotion is a discouraging factor. Item "Employees confidential evaluation reports are accounted for" scored the lowest mean. This influences the employees' performance and the organization performance. 
Table 5

The mean and standard deviation of the factors associated with evaluation and promotion

\begin{tabular}{|c|c|c|c|c|c|}
\hline & Item & Mean & $\begin{array}{l}\text { Std. } \\
\text { dev. }\end{array}$ & Rank & Level \\
\hline 1 & $\begin{array}{l}\text { Employees are evaluated by standards different from the approved evaluation standards they } \\
\text { should have }\end{array}$ & 2.797 & 0.882 & 5 & Intermediate \\
\hline 2 & Employees confidential evaluation reports are accounted for & 2.582 & 0.652 & 6 & Intermediate \\
\hline 3 & All employees are treated equally & 2.987 & 0.650 & 2 & Intermediate \\
\hline 4 & Employees at Jadara university are accountable for work attendance without bias & 2.924 & 0.828 & 3 & Intermediate \\
\hline 5 & $\begin{array}{l}\text { Management bias for some employees at Jadara university influences the performance of } \\
\text { other employees negatively }\end{array}$ & 3.265 & 0.634 & 1 & Intermediate \\
\hline 6 & $\begin{array}{l}\text { Management bias for some employees at Jadara university influences the coworker's rela- } \\
\text { tions negatively. }\end{array}$ & 2.822 & 0.763 & 4 & Intermediate \\
\hline & Overall & 2.896 & 0.323 & & Intermediate \\
\hline
\end{tabular}

Table 6

The mean and standard deviation of the factors associated with incentives and rewards

\begin{tabular}{|c|c|c|c|c|c|}
\hline & Item & Mean & $\begin{array}{l}\text { Std. } \\
\text { dev. }\end{array}$ & Rank & Level \\
\hline 1 & Jadara university employees are promoted according to equally standards without bias & 2.696 & 0.704 & 3 & Intermediate \\
\hline 2 & $\begin{array}{l}\text { Jadara university employees are offered bonuses and rewards without bias according to the } \\
\text { approved system }\end{array}$ & 2.658 & 0.677 & 4 & Intermediate \\
\hline 3 & Employees mistakes are treated equally without bias & 2.759 & 0.908 & 2 & Intermediate \\
\hline \multirow[t]{2}{*}{4} & $\begin{array}{l}\text { Incentives and rewards are offered to employees without biasness which reflects on attend- } \\
\text { ance, leaves and holiday }\end{array}$ & 3.177 & 0.746 & 1 & Intermediate \\
\hline & Overall & 2.822 & 0.501 & & Intermediate \\
\hline
\end{tabular}

According to Table 6, it can be verified that the information of mean and standard deviation of incentives and rewards were intermediate; the highest mean (3.177) belongs to "Incentives and rewards are offered to employees without biasness which reflects on attendance, leaves and holiday.", which indicates that biased employees waste official working hours, which in turn influence performance, completing tasks, and achieving goals. The other items scores are very close.

Table 7

The mean and standard deviation of the factors associated with job security

\begin{tabular}{|c|c|c|c|c|c|}
\hline & Item & $\begin{array}{c}\text { Mea } \\
n\end{array}$ & $\begin{array}{l}\text { Std. } \\
\text { dev. }\end{array}$ & Rank & Level \\
\hline 1 & Employees confidential evaluation reports are considered upon contracts renewal & 2.569 & 0.762 & 4 & Intermediate \\
\hline 2 & Employees are offered permanent contracts without bias & 2.405 & 0.759 & 5 & Intermediate \\
\hline 3 & Employees job security levels are equal which enhances performance & 2.873 & 0.757 & 3 & Intermediate \\
\hline 4 & The university adopts job security of employees to enhance their satisfaction & 3.113 & 0.750 & 1 & Intermediate \\
\hline \multirow{2}{*}{\multicolumn{2}{|c|}{$\frac{\text { The university adopts job security equality of employees to enhance their friendliness relations }}{\text { Overall }}$}} & 2.886 & 0.767 & 2 & Intermediate \\
\hline & & 2.822 & 0.501 & & Intermediate \\
\hline
\end{tabular}

Table 7 illustrates the means and standard deviations of job security dimension, the highest mean (3.113) is scored by item "The university adopts job security of employees to enhance their satisfaction," which means that unbiased employees are unsatisfied because they do not feel secured in their jobs, so their performance degenerated. Item "Employees are offered permanent contracts without bias" scored the lowest mean degree (2.405); which means that biased management would not always offer permanent contracts.

Table 8

The mean and standard deviation of the factors associated with empowerment

\begin{tabular}{|c|c|c|c|c|c|}
\hline & Item & Mean & $\begin{array}{l}\text { Std. } \\
\text { dev. }\end{array}$ & Rank & Level \\
\hline 1 & Employees offered authorities suit the work volume assigned to them & 2.632 & 0.719 & 1 & Intermediate \\
\hline 2 & The university management fairly allows the employees to acquire new skills & 2.594 & 0.884 & 3 & Intermediate \\
\hline 3 & $\begin{array}{l}\text { The university management provides all employees with the proper facilities to perform } \\
\text { their tasks. }\end{array}$ & 2.519 & 0.657 & 5 & Intermediate \\
\hline 4 & Employees are all offered the same opportunities to perform tasks and duties & 2.151 & 0.785 & 6 & Intermediate \\
\hline 5 & $\begin{array}{l}\text { Legislations implemented at Jadara university facilitate the performance of all administra- } \\
\text { tive employees. }\end{array}$ & 2.594 & 0.670 & 2 & Intermediate \\
\hline 6 & $\begin{array}{l}\text { The university administrations ensure separation of authorities between different administra- } \\
\text { tive units. }\end{array}$ & 2.569 & 0.745 & 4 & Intermediate \\
\hline \multicolumn{2}{|r|}{ Overall } & 2.510 & 0.529 & & Intermediate \\
\hline
\end{tabular}

Table 8 demonstrates the information of mean and standard deviation of empowerment, the lowest mean (2.151) is scored by item "Administrative employees are all offered the same opportunities to perform tasks and duties," and the level of empowerment bias is intermediate, the other items scores are very close. Finally, Table 9 illustrates the information of mean and standard deviation of performance variable. The lowest score (M. =2.253) belongs to "Management bias influences the level of job loyalty in the university," which means that the level of job loyalty is low because of management bias practices. 
The highest score $(M .=3.303)$ belongs to "Practicing of management bias influences work performance in general," which means that management bias influences performance in general.

Table 9

The mean and standard deviation of the factors associated with performance level

\begin{tabular}{|c|c|c|c|c|c|}
\hline $\begin{array}{l}\text { Item } \\
\text { No. }\end{array}$ & Item & Mean & Std. & Rank & Level \\
\hline 1 & Practicing of management bias influences work performance in general & 3.303 & 0.606 & 1 & Intermediate \\
\hline 2 & Management bias influences the size of knowledge that the employees add to their departments & 2.557 & 0.674 & 7 & Intermediate \\
\hline 3 & $\begin{array}{l}\text { Management bias influences the quality of decision making which participate in performance } \\
\text { enhancement }\end{array}$ & 2.329 & 0.843 & 10 & Intermediate \\
\hline 4 & Management bias influences the level of employees working in administrative control centers & 2.240 & 0.771 & 13 & Intermediate \\
\hline 5 & Management bias increase quitting work voluntary & 2.493 & 0.814 & 8 & Intermediate \\
\hline 6 & Employees benefit from training in developing work and enhancing performance & 2.848 & 0.785 & 4 & Intermediate \\
\hline 7 & $\begin{array}{l}\text { Promoting employees from the university to leadership jobs is an important reason of perfor- } \\
\text { mance enhancement }\end{array}$ & 2.924 & 0.747 & 3 & Intermediate \\
\hline 8 & Management bias influences the level of job loyalty in the university & 2.253 & 0.775 & 12 & Intermediate \\
\hline 9 & $\begin{array}{l}\text { Management bias influences employees' opportunities to develop the professional abilities to } \\
\text { enhance performance }\end{array}$ & 3.025 & 0.697 & 2 & Intermediate \\
\hline 10 & Management bias influences the level of work time investment for working & 2.278 & 0.714 & 11 & Intermediate \\
\hline 11 & Management bias participate in increasing the number of low performance employees & 2.455 & 0.694 & 9 & Intermediate \\
\hline 12 & Management bias influences the sick leaves used by the employees & 2.569 & 0.857 & 6 & Intermediate \\
\hline Overall & & 2.606 & 0.355 & 5 & Intermediate \\
\hline
\end{tabular}

\section{Testing the Study Hypotheses}

To test the main hypothesis, "There is no statistically significant difference at $(\alpha \leq 0.05)$ of management bias practice and its various dimensions on employee's performance at Jadara University," The study computes the multiple regression of management bias and its variables effect on performance and the results are given in Table 10.

Table 10

The results of regression analysis

\begin{tabular}{|c|c|c|c|c|c|c|}
\hline Independent variable & $\beta$ & Std. & $\mathrm{R}$ & $\mathrm{R}^{2}$ & $\mathrm{~F}$ & Sign. \\
\hline Selection and recruitment & 0.32 & 0.07 & \multirow{5}{*}{0.64} & \multirow{5}{*}{0.41} & \multirow{5}{*}{14.13} & \multirow{5}{*}{0.00} \\
\hline Evaluation and promotion & 0.42 & 0.08 & & & & \\
\hline Incentives and rewards & 0.37 & 0.06 & & & & \\
\hline Job security & 0.45 & 0.07 & & & & \\
\hline Empowerment & 0.39 & 0.05 & & & & \\
\hline
\end{tabular}

According to the results of Table 10, F-value is statistically meaningful when the level of significance is one percent. The result of R-Square indicates that the regression describes approximately 41 percent of the changes on employee performance. All independent variables have positive coefficients which means they positively influence on employee performance. Table 11 summarizes the results of testing the hypotheses.

\section{Table 11}

The results of simple linear regression

\begin{tabular}{lllllllll}
\hline Dependent variables & $\beta$ & $\mathrm{T}$ & Sig. & $\mathrm{R}$ & $\mathrm{R} 2$ & $\mathrm{~F}$ & Sig. & Acceptance \\
\hline H1: Selection and recruitment & 0.32 & 2.78 & 0.00 & 0.50 & 0.25 & 10.30 & 0.00 & Accepted \\
H2: Evaluation and promotion & 0.42 & 2.79 & 0.00 & 0.48 & 0.23 & 3.96 & 0.00 & Accepted \\
H3: Incentives and rewards & 0.37 & 3.45 & 0.00 & 0.67 & 0.45 & 8.14 & 0.00 & Accepted \\
H4: Job security & 0.45 & 3.63 & 0.00 & 0.47 & 0.22 & 6.77 & 0.00 & Accepted \\
H5: Empowerment & 0.39 & 3.41 & 0.00 & 0.60 & 0.36 & 6.74 & 0.00 & Accepted \\
\hline
\end{tabular}

\section{Results and recommendations}

Job performance plays an essential role for the success of organizations. Any organization with skilled employee will be able to improve the performance of the organizations. However, when the management uses a bias method for hiring employee, we may expect some unpleasant results. This paper has presented an empirical investigation to study the effects of management bias on job performance at Jadara University. The study has measured the effects of five variables; namely selection and recruitment, evaluation and promotion, incentives and rewards, job security and empowerment on job performance. The results have indicated that all mentioned variables have meaningful effects on job performance. Thus, it is also recommended to adopt clear criteria in the processes of evaluation and promotion. Another recommendation is to establish the system of incentives and rewards with clear principals and apply it fairly on all employees. Furthermore, it is recommended to sign long-term contracts with employees to secure the, in their job, so their loyalty increases. Moreover, Jadara University should involve and empower employees in decision-making. Lastly, the university should concentrate on performance (scored low 
levels) because it is the centerpiece of the overall management success in the university and a main supporter for the academic process.

\section{References}

Abo Al-Azem, F. (2015). The relationship between balanced scorecard characteristics and innovation: evidence from Egypt. New York Science Journal 6(4): 62-73.

Al-Gharaibeh, S. M., \& Malkawi, N. M. (2013). The impact of management information systems on the performance of governmental organizations-Study at Jordanian ministry of planning. International Journal of Business and Social Science, 4(17), 101-109.

Aljawarneh, N. M. S., \&Atan, T. (2018). Linking tolerance to workplace incivility, service innovation, knowledge hiding, and job search behavior: The mediating role of employee cynicism. Negotiation and Conflict Management Research, 11(4), 298-320.

Aljawarneh, N., \& Al-Omari, Z. (2018). The role of enterprise resource planning systems ERP in improving customer relationship management CRM: An empirical study of safe way company of Jordan. International Journal of Business and Management, 13(8), 86-100.

Al-Khasawneh, A. L., Malkawi, N. M., \& AlGarni, A. A. (2018). Sources of recruitment at foreign commercial banks in Jordan and their impact on the job performance proficiency. Banks and Bank Systems, 13(2), 12.

Al-Sa'doon, F.M.. (2013). The role of the Professional Training Programs in Improving Employees Performance. (Unpublished master's thesis). Faculty of Management. Naif Arab University for Security Sciences.

Al-Omari, Z., Alomari, K., \& Aljawarneh, N. (2020). The role of empowerment in improving internal process, customer satisfaction, learning and growth. Management Science Letters, 10 (4), 841-848.

Bani Hani, J., Al-Ahmad, N., \& Al-Najjar, F. (2009). The impact of management information systems on organization performance: Field study at Jordanian universities. Review of Business Research -RPR, 9(2), 127-138.

Bol, J. (2011). Determinants and performance effects of managers' performance evaluation biases. The Accounting Review, $86(5), 1549-1575$.

Dodeen, A. (2009). The role of knowledge management and information technology in achieving competitiveness in working banks in Gaza Stripe. Zarqa Journal for Research and Humanities, 9(2).

Freimuth, H. (2014). Cultural bias in university entrance examinations In the UAE. The Emirates Occasional Papers, (85), $0 \_1$.

Haje-an, N. (3011). Bias is the beginning of Tyranny. Riyadh newspaper, No. 15669. Retrieved on 1/2/2019. http://www.alriyadh.com/633914

Haroon, A.A.M. (1990). Tahqū̄qāt wa-tanbīhāt fì mu‘jam Lisān al-'Arab. KING ABDULAZIZ UNIVERSITY. https://waqfeya.com/book.php?bid=12648

Ibrahim, S. (2004). Management Information Systems. Alexandria-Egypt: El Dar El Gamaya for Publishing.

Kagaari, J., Munene, J. C., \& Mpeera Ntayi, J. (2010). Performance management practices, employee attitudes and managed performance. International Journal of Educational Management, 24(6), 507-530.

Kaplan, R., \& D. Norton. (1996). The Balanced Scorecard. Boston: Harvard Business School, Press.

Malkawi, N., \& AL Omari, K. (2018). The role of organizational justice in managing organizational conflict -Case study at Jordanian Marseilles company for real estate investments / Irbid City Center- Irbid- Jordan. European Journal of Economics, Finance and Administrative Sciences, 98.

Martin, B. H. (2017). Unsticking the status quo: Strategic framing effects on managerial mindset, status quo bias and systematic resistance to change. Management Research Review, 40(2), 122-141.

Mostafa, S. (2009). Until when bias and favoritism will influence performance in our societies and organizations. Retrieved on 30/3/2019. http://www.dampress.net/?page=show det\&category $\mathrm{id}=\& \mathrm{id}=4474$

Prater, J., Kirytopoulos, K., \& Ma, T. (2017). Optimism bias within the project management context: a systematic quantitative literature review. International Journal of Managing Projects in Business, 10(2), 370-385.

Talal, N.N.A. (2013). The impact of managerial innovation on improving the level of human resources management performance in Jordanian commercial banks. International Innovation and Organizational Change in Modern Organizations symposium: Study and Analysis of National and International Experiences in Algeria: Saad Dahlab Blida University.

Thabit, T. (2015). Applying fuzzy logic to evaluate the bsc's performance for a random private Iraqi banks group. International Journal of Banking, Finance \& Digital Marketing, 1(1), 42-54.

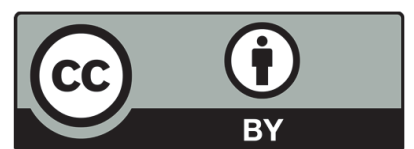

(C) 2020 by the authors; licensee Growing Science, Canada. This is an open access article distributed under the terms and conditions of the Creative Commons Attribution (CC-BY) license (http://creativecommons.org/licenses/by/4.0/). 